\title{
Consumer acceptance of novel vegetable containing bread products as a potential vehicle to increase vegetable consumption
}

\author{
D. A. Hobbs ${ }^{1,2}$, T. W. George ${ }^{1,2}$, J. A. Lovegrove ${ }^{1,2}$ and L. Methven ${ }^{1}$ \\ ${ }^{1}$ Department of Food and Nutritional Sciences and ${ }^{2}$ Institute for Cardiovascular and Metabolic Research (ICMR), \\ University of Reading, Whiteknights, PO Box 226, Reading, Berks, RG6 6AP, UK
}

Daily intakes of $400 \mathrm{~g}$ of fruits and vegetables are recommended in the UK for the prevention of chronic diseases ${ }^{(1)}$. Despite initiatives to increase consumption, current fruit and vegetable intake is below recommendations ${ }^{(2)}$. Bread is consumed by the majority of people in Western societies and is particularly amenable to vegetable inclusion. Therefore, enriching bread with vegetables may be a potential vehicle to increase vegetable consumption. The aim of this study was to investigate consumer acceptance of bread products containing vegetables.

A trained panel measured sensory attributes of five bread products enriched with either $80 \mathrm{~g}$ red beetroot, white beetroot, carrot or red pepper per $200 \mathrm{~g}$ ( 2 slices) or white control bread (no vegetable inclusion) by descriptive analysis using 76 attributes. In addition, 120 regular bread consumers ( $>4$ slices bread/week) gave liking, purchase intent and product replacement ratings of the breads using nine point hedonic scales in a central location. Supplementary information about consumption frequency of vegetables and general interest in nutrition were also asked.

Ratings showed a significant difference in liking between the breads by consumers $(P=<0.0001)$. Multiple pair-wise comparisons revealed no significant differences in liking between bread enriched with white beetroot and white control bread. Internal preference mapping showed that red beetroot enriched bread was least liked by consumers. However, the difference was driven by colour not flavour as the latter was equivalent in both beetroot variants. Hierarchal cluster analysis of consumer liking data showed that it was possible to divide the consumers into 6 clusters, 3 of which included substantial consumer numbers. One group (24.2\%) preferred bread enriched with white beetroot, another $(55.8 \%)$ with red pepper, the final group $(10.8 \%)$ preferred white control bread. A similar trend emerged for purchase intent and product replacement.

Consequently, this study suggests that enriching bread with vegetables may be an accepted vehicle to increase vegetable consumption.

1. Murray C, Lopez A (2002) World Health Report 2002: Reducing Risks, Promoting Healthy Life. Geneva, World Health Organisation.

2. Bates B, Lennox A, Swan G (2010) National Diet and Nutrition Survey. Headline Results from Year of the Rolling Programme (2008/09). Food Standards Agency/Department of Health: London. 